\title{
Hydrothermal Synthesis and Characterization of Zeolite A from Grahamstown South Africa Kaolin
}

\author{
U M Aliyu*, S Rathilal, S I Mustapha and Y M Isa.
}

\begin{abstract}
Zeolite A was synthesized using natural south African kaolin from Graham's town mineral resource as a source of silica and alumina. The raw kaolin was beneficiated mechanically, and the kaolin was activated to metakaolin using the muffled furnace at $650^{\circ} \mathrm{C}$ for 3 hours. Zeolite A was hydrothermally synthesis in $\mathrm{NaOH}$ solutions of different concentrations of 1.0 to 4.0 molar at crystallization time and temperature of $20 \mathrm{~h}$ and $100^{\circ} \mathrm{C}$, respectively. The metakaolin and sodium hydroxide solution ratio of $1.2 \mathrm{~g} / 25 \mathrm{ml}$ solid/liquid was used. The raw, beneficiated kaolin and the synthesized zeolite A samples were characterized by X-Ray Fluorescence (XRF), Thermogravimetric analysis (TGA), Scanning electron microscopy (SEM), X-Ray diffraction (XRD), and Fourier-transform infrared spectroscopy (FTIR). A round-headed cubic crystal of zeolite A obtained was accompanied by quartz and mica impurities and matched well compared with a reference zeolite A sample.
\end{abstract}

Keywords - Beneficiation, $\mathrm{NaOH}$ solution, South African kaolin, Zeolite A.

\section{INTRODUCTION}

Zeolites are microporous three dimensional crystalline, hydrated aluminosilicate resources, with vast scientific and engineering consequences in the field of separation such as purification, ion exchange, solid catalyst [1]. The frameworks characterized by $\{\mathrm{SiO} 4\} 4$ and $\{\mathrm{AlO} 4\} 5$ tetrahedral units that formulate a structure of consistent pore with a similar arrangement and physicochemical properties [2]. Several natural zeolites have been exposed around the globe, and the uses of these natural resources are attracting attention from academics and industries. Despite the availability and freely in nature, natural zeolites cannot satisfy all the needs for numerous industrial applications. This is as a result of impurities,

Manuscript received September 28, 2020. Acknowledgment

The authors wish to appreciate and acknowledged the financial support from Umgeni water, Durban, KZN South Africa.

U. M. Aliyu is with the Fuels and Petrochemicals Group, Department of Chemical Engineering, Durban University of Technology, Durban 4000, South Africa

S. Rathilal is with Department of Chemical Engineering, Durban University of Technology, Durban 4000, South Africa.

S. I. Mustapha is with the Fuels and Petrochemicals Group, Department of Chemical Engineering, Durban University of Technology, Durban 4000, South Africa.

Y. M. Isa is with the Fuels and Petrochemicals Group, Department of Chemical Engineering, Durban University of Technology, Durban 4000, South Africa. non-uniform pore size in their structure and low ion-exchange capacities [1]-[7]. The presence of impurities in natural zeolites encouraged the industrial sector to pay more attention to synthetic zeolites.

The early synthesis of zeolite was from chemical substances such as sodium silicate, sodium hydroxide, sodium aluminate and tetraethylorthosilicate (TEOS) [6], [8], [9]. The main chemical composition of zeolite A are silica and alumina and are widely available in natural material such as rocks and minerals [3]. Recently, zeolite A is synthesized using natural resources such as kaolinite [1], [7], coal ashes, municipal solid wastes, and industrial sludge [10]. The availability of cheap kaolin clay attracts attention due to its reach in kaolinite contents. The kaolinite is mostly composed of silica and alumina which made the synthesis of zeolite A cheaper and more affordable compare to the synthesis using expensive chemical.

There are two steps involved in the synthesis of zeolite A using kaolin as a replacement of silica and alumina: metakaolinization (calcination) of inert kaolin to more stable reactive amorphous material using a furnace to get metakaolin. Secondly, the hydrothermal synthesis of the metakaolin with sodium hydroxide solution at a control parameter such as temperature, time and ageing [7], [9], [11]. Ayele and his co-workers [9] reported the production of zeolite A by hydrothermal conventional synthesis method and alkaline fusion first before hydrothermal treatment. By applying the first method, a combination of various zeolite structures such as sodalite was detected and using alkaline fusion route synthesis of pure zeolite is promoted. Despite the extensive application of kaolin for the synthesis of zeolite A under different parameter and to the best knowledge of the authors, no effort has been made hitherto to synthesized zeolite A from the much abundant natural Grahamstown kaolin of eastern Cape south Africa. Grahams town kaolin mineral resources deposit is located at coordinate $26.2634^{\circ} \mathrm{S}, 28.1966^{\circ} \mathrm{E}$ in the Eastern Cape province of South Africa with rich endowed minerals resources. In this report, zeolite $A$ was synthesized from $G \& W$ Grahamstown kaolin by conventional hydrothermal process. The efficiency of sodium hydroxide concentrations (1.0, 2.0, 3.0 , and $4.0 \mathrm{M} \mathrm{NaOH}$ ) was examined. The beneficiated metakaolin, the raw kaolin and the produced zeolite A samples were characterized by X-ray fluorescence (XRF), X-ray diffraction (XRD), scanning electron microscopy (SEM) and Fourier transform infrared spectroscopy (FTIR). 


\section{MATERIALS AND METHOD}

\section{A. Kaolin and beneficiation}

Raw kaolin was donated by G\&W mineral resources factory located in the eastern part of Cape province of South Africa. The raw clay (kaolin) directly from the source was dispersed in deionized water and mixed thoroughly by stirring manually using iron stirrer for about 1 hour without adding any dispersant or adjusting the $\mathrm{pH}$. The solution was allowed to settle by gravity for 10min before decanting. The slurry was transferred into a glass separating funnel and allowed to settle for 48 hours before decanting into two portions namely top (TP) and bottom (BP) products. The bottom contains a significant amount of impurities while the top product contains less quartz content. The bottom product was discarded and the top product was kept for the synthesis experiments. These procedures were adequate in boosting the purity of the kaolin and is a fundamental operation for the synthesis of zeolite A. These compositions were dried in an oven at $105^{\circ} \mathrm{C}$ until a stable weight was attained. The kaolin was activated to metakaolin using the muffled furnace at $650^{\circ} \mathrm{C}$ for 30 minutes. Chemical composition and Typical mineralogy weight $\%$ of the metakaolin is presented in table 1. Analytical grade of $\mathrm{NaOH}$ was purchased from Aldrich. The characterization was performed using X-ray diffraction machine Bruker AXS, D8.and XRF analysis.

\section{B. Hydrothermal synthesis of zeolite A}

The hydrothermal synthesis procedure was used to produced zeolite A using metakaolin as a source of silica and alumina. The kaolin was activated to metakaolin using the muffled furnace at $650^{\circ} \mathrm{C}$ for 3 hours. The effect of synthesis parameters (crystallization temperature, time and ageing) was controlled and optimized for the best synthesis condition of zeolite A synthesis. Metakaolin was treated in a 1, 2, 3, 4 M solution of sodium hydroxide. The mixture was homogenized by stirring slowly for $10 \mathrm{~min}$ at room temperature. The metakaolin and sodium hydroxide solution ratio of $1.2 \mathrm{~g} / 25 \mathrm{ml}$ [7]. The reaction mixture was then stirred vigorously for $30 \mathrm{~min}$ at stirring speed of 600rpm. The obtained sol-gel was aged for 12 hours at room temperature. The aged sample was crystallized at $100^{\circ} \mathrm{C}$ for 20 hours under autogenous pressure. The products were filtered and washed with distilled water 3 to 4 times using a vacuum filtration pump set up. The zeolite was dried at $80^{\circ} \mathrm{C}$ overnight. The products were packaged in a container for characterizations.

\section{Characterization techniques}

The morphology was characterized by using scanning electron microscopy FEI Nova NanoSEM 230 with a field emission gun equipped with a high-resolution immersion lens. The EDS detector is an Oxford X-Max, using INCA software. Thermal analysis was done using thermogravimetric analyzer/differential scanning calorimetry (TGA/DSC 1) STAR System Mettle Toledo. X-ray diffraction (XRD) patterns and average crystallite size were collected with Bruker AXS, D8 Advance equipped with Tube $(\mathrm{Cu}-\mathrm{Ka}$ radiation $(1 \mathrm{Ka} 1=1.5406 \AA)$ and Detectors Lynx Eye (Position sensitive detector) at $40 \mathrm{kV}, 40 \mathrm{~mA}$ and $\mathrm{V} 20$ variable slit. The measurements were carried out with a step width of $0.5^{\circ}$ to $130^{\circ}$ $2 \theta$ with an increment $\left(\Delta 2 \theta\right.$ of $0.034^{\circ}$ and a scan rate of $0.5 \mathrm{sec}$ per step. The diffraction data were analyzed using OriginPro 2018 software to give the estimation of the amount of each phase in the sample. The bands were measured using FTIR machine equipped with universal attenuated total reflectance (ATR), Perkin Elmer spectrum two.

\section{RESULTS AND DISCUSSION}

\section{A. Metakaolinization}

The most fundamental step in the production of zeolite A is the conversion of inert kaolin by reactivation using a metakaolinization process to get a reactive phase. The XRD pattern of the raw and calcined kaolin is depicted in Fig. 1. The XRD pattern of the calcined kaolin shows a significant difference when compared with the un-calcined sample. The characteristics peaks of kaolin at $2 \Theta=12.4$ and $24.6^{\circ}$ disappeared and complemented by the appearance of amorphous aluminosilicate between $2 \Theta=12$ to $39^{\circ}$ [12]. The appearance of this amorphous aluminosilicate is characteristic X-ray diffraction pattern of calcined kaolin known as metakaolin. This amorphous aluminosilicate is accompanied by the presence of intense diffraction peaks of mica and quartz at $2 \Theta=7.8$ and $26.5^{\circ}$ respectively. Despite the high calcination temperature of $650^{\circ} \mathrm{C}$, the diffraction peaks of mica and quartz remained significant in this work. The SEM micrographs of kaolin and metakaolin (Fig.3) clearly show the effect of the thermal transformation of kaolin to metakaolin. The SEM images indicate the disappearance of platelet stacking arrangement layered kaolin shape with the formation of cloudy shapeless morphology structure of metakaolin.

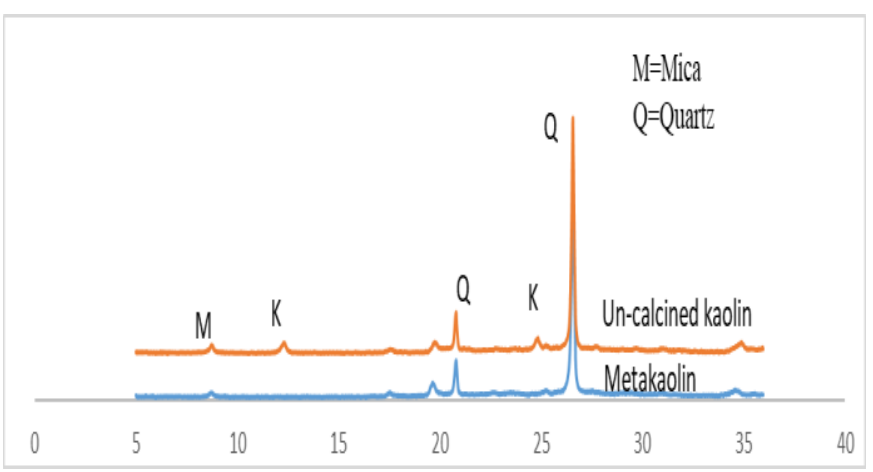

Fig. 1. The XRD pattern of beneficiated kaolin and metakaolin kaolin calcined at $650^{\circ} \mathrm{C}$ 


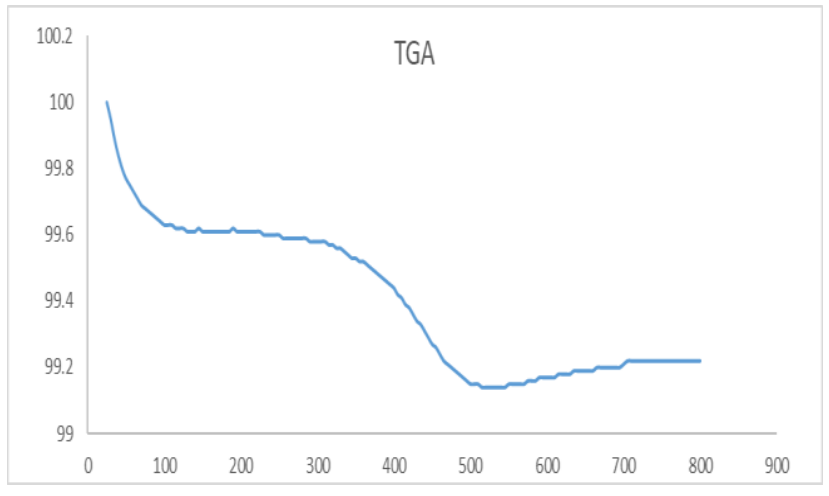

Fig. 2. Thermogravimetric analysis of beneficiated kaolin

TABLE I: XRF ANALYSIS OF BENEFICIATED KAOLIN

\begin{tabular}{|c|c|c|c|c|c|}
\hline \multirow[t]{2}{*}{ Composition } & \multirow[t]{2}{*}{$\begin{array}{l}\text { Raw } \\
\text { kaolin \% }\end{array}$} & \multirow{2}{*}{$\begin{array}{l}\text { Beneficiated } \\
\text { Metakaolin } \\
\%\end{array}$} & \multicolumn{3}{|c|}{$\begin{array}{c}\text { Typical mineralogical } \\
\text { weight } \%\end{array}$} \\
\hline & & & Raw & & ated \\
\hline $\mathrm{SiO}_{2}$ & 66.58 & 64.87 & Mica & 14 & 11 \\
\hline $\mathrm{TiO}_{2}$ & 0.57 & 1.26 & quartz & 49 & 34 \\
\hline $\mathrm{Al}_{2} \mathrm{O}_{3}$ & 22.81 & 21.64 & kaolinite & 37 & 39 \\
\hline $\mathrm{Fe} 2 \mathrm{O}_{3}$ & 0.87 & 0.57 & & & \\
\hline $\mathrm{MnO}$ & 0.010 & - & & & \\
\hline $\mathrm{MgO}$ & $<0.01$ & - & & & \\
\hline $\mathrm{CaO}$ & 0.12 & 0.16 & & & \\
\hline $\mathrm{Na}_{2} \mathrm{O}$ & 0.29 & 0.31 & & & \\
\hline $\mathrm{K} 2 \mathrm{O}$ & 2.01 & 1.46 & & & \\
\hline $\mathrm{P}_{2} \mathrm{O}_{5}$ & 0.289 & 0.205 & & & \\
\hline $\mathrm{Cr}_{2} \mathrm{O}_{3}$ & 0.361 & 0.288 & & & \\
\hline L.O.I. & 6.10 & 7.12 & & & \\
\hline Total & 99.98 & 97.88 & & & \\
\hline $\mathrm{H} 2 \mathrm{O}$ & 1.57 & - & & & \\
\hline
\end{tabular}

However, the chemical composition analysis of the raw and beneficiated kaolin is shown in table 1 . The results show that the kaolin is rich in the oxide of potassium and the effect of beneficiation is reflecting by low contents of oxide of iron, calcium, sodium, phosphorus, chromium. Titanium, magnesium, and manganese. The results presented the outcome of beneficiated metakaolin over the raw kaolin showing the significance of the silica reduction from $66.58 \%$ to $64.87 \%$ as a result of the removal of quartz from the raw clay. The white colouration of the kaolin is ascribed to a substantial amount of $\mathrm{TiO}_{2}$ presence. Mica and Quartz impurities presented a significant reduction of their content from 14 to $11 \mathrm{wt} \%$ and 49 to 34 wt. $\%$ for mica and quartz respectively. The thermogravimetric analysis (TGA) shows the thermal stability of the metakaolin clay (Fig.2) which is the initial material for the synthesis of zeolite A. The conversion of the kaolin to metakaolin was detected at region $525^{\circ} \mathrm{C}$. The first weight loss occurs at a region below $105^{\circ} \mathrm{C}$ with about 0.39 wt. \% loss as a result of dehydration of absorbed water from the kaolin. The highest weight loss of $0.86 \mathrm{wt}$ \% occurred in the region of 335 to 600 . It' $\mathrm{s}$ the weight loss due to the restructuring in the kaolin tetrahedral layer. The total weight loss is less than $1 \%$
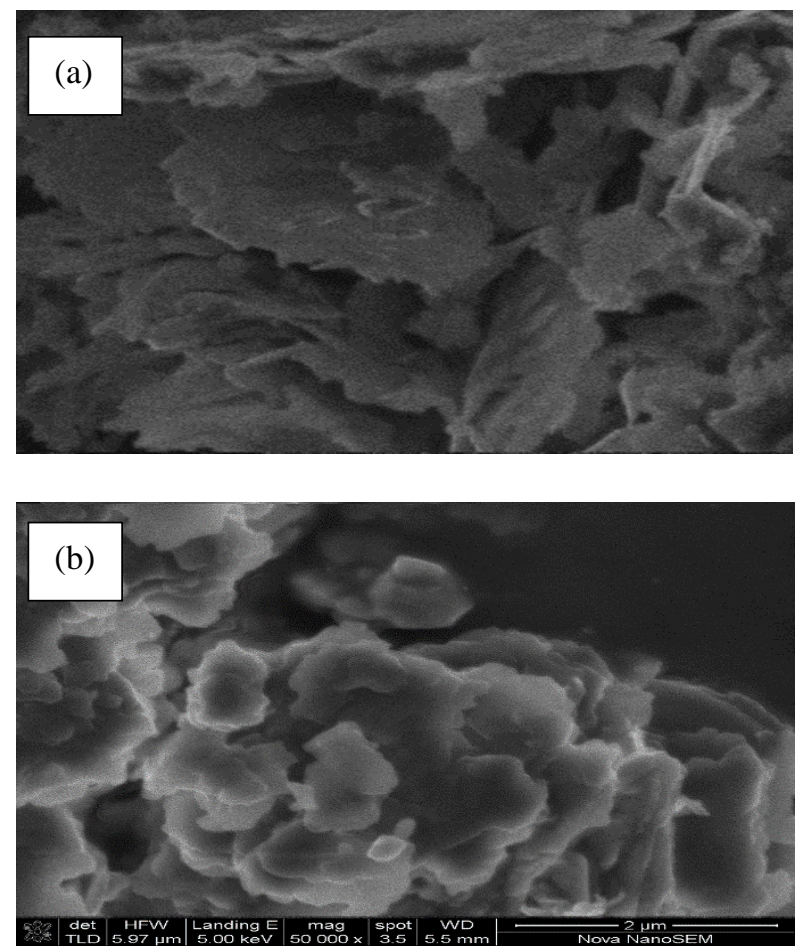

Fig. 3. The SEM micrograph of (a) kaolin and (b) metakaolin

\section{B. X-ray diffraction}

The X-ray diffraction of zeolite A formation from the reaction of metakaolin and solution of 1.0, 2.0, 3.0, and 4.0 molar sodium hydroxide solution at a crystallization temperature of $100^{\circ} \mathrm{C}$, the reaction time of $20 \mathrm{~h}$ and a reference sample of zeolite A is depicted in Figure 3. The conversion of metakaolin to zeolite A was confirmed by matching the 2-theta angle values of the synthesized zeolite A with the reference sample. The characteristic peaks of the synthesized zeolite A matched well with characteristic peaks of the reference sample at the 2-theta value of $7.2^{\circ}, 10.2^{\circ}, 12.5^{\circ}, 16.1^{\circ}, 21.7^{\circ}$, and $24^{\circ}$ [13]. Figure 4, shows the XRD pattern of the synthesized zeolite A. It can be seen in the XRD patterns that the characteristic peaks of zeolite A appeared in $2 \mathrm{M} \mathrm{NaOH}$ which matched perfectly with the reference sample [7], [10]. Though there was the appearance of zeolite A formation in all the synthesis under the optimized $\mathrm{NaOH}$ molar concentration, the best crystallinity was attained under $4 \mathrm{M} \mathrm{NaOH}$ solution from the solid/liquid ratio $1.2 \mathrm{~g} / 25 \mathrm{ml}$ [10]. It appears from the intensities of the peaks that the synthesized zeolite $\mathrm{A}$ at $4 \mathrm{M} \mathrm{NaOH}$ concentrations is more intense than the reference zeolite A. However, the XRD pattern of the synthesized zeolite product ( 2 and $3 \mathrm{M}$ ) contains zeolite $\mathrm{A}$ as the main component and accompanied by hydroxysodalite (HS) appearance at 8.4 and quartz impurities at 
20.7 and 26.62 -theta values.

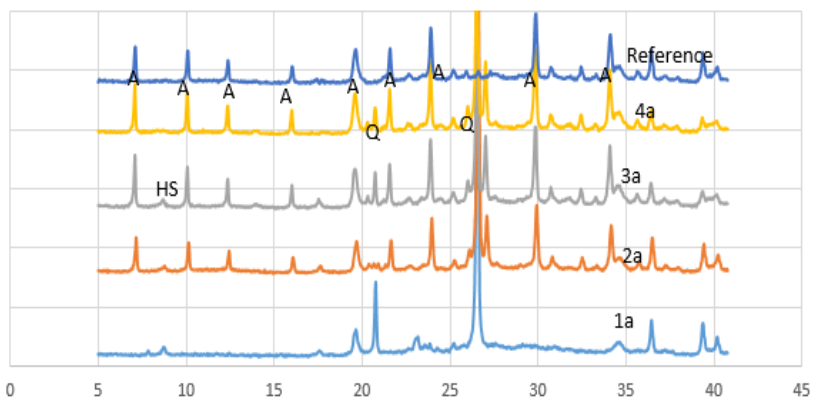

Fig. 4. the XRD pattern of synthesized zeolite A achieved by hydrothermal crystallization (1a) $1.0 \mathrm{M} \mathrm{NaOH}$, (2b) $2.0 \mathrm{M} \mathrm{NaOH} \mathrm{(3a)}$ 3.0 $\mathrm{M} \mathrm{NaOH}$, (4a) 4.0 M NaOH and Reference zeolite A.

\section{SEM Morphology}

SEM morphology of the metakaolin treatment in different concentration of $\mathrm{NaOH}$ and crystallized hydrothermally yields excellent result. Fig. 5a-c characterized the outcomes of various alkaline $(\mathrm{NaOH})$ concentration $2 \mathrm{M}, 3 \mathrm{M}$, and $4 \mathrm{M} \mathrm{NaOH}$ on the production of zeolite $\mathrm{A}$ at $100^{\circ} \mathrm{C}$ and $20 \mathrm{~h}$. The micrograph result obtained in this experiment is comparable to the reported work by various researchers [7], [10], [11]. The SEM morphology obtained at $1.0 \mathrm{M} \mathrm{NaOH}$ solution show no formation of zeolite $\mathrm{A}$ and this corroborates with the XRD result where no zeolite was developed at $1 \mathrm{M}$ concentration. When the concentration increased to $2 \mathrm{M}$, a crystalline cubic round-headed zeolite A morphology was established which is accompanied by undissolved metakaolin and amorphous material of unconverted quartz were seen in the sample figure $4 \mathrm{a}$. By increasing the $\mathrm{NaOH}$ concentration to $3 \mathrm{M}$, well-defined cubic crystals zeolite A was formed with unreacted silica and quartz and the presence of Hydroxysodalite peak was confirm. When the $\mathrm{NaOH}$ concentrations increased to $4 \mathrm{M}$, the SEM images of the treated metakaolin demonstrate mainly more cubic crystal of zeolite A was observed though there is some unreacted amorphous aluminosilicate.

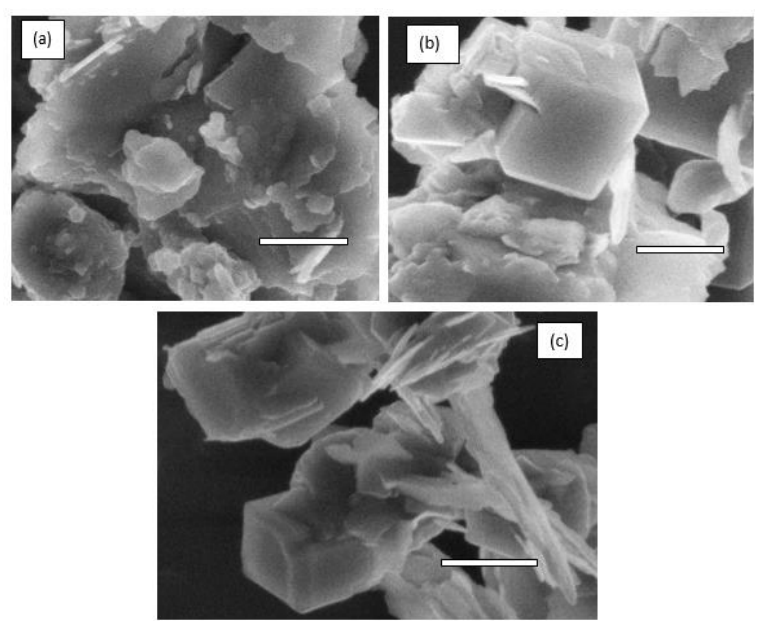

Fig. 5. The SEM micrograph of zeolite A synthesized at (a) $2 \mathrm{M} \mathrm{NaOH}$ (b) $3 \mathrm{M} \mathrm{NaOH}$ (c) $4 \mathrm{M} \mathrm{NaOH}$ solutions. Scale bar $1 \mu \mathrm{m}$

\section{FTIR analysis}

The FTIR spectra of synthesized zeolite A samples produced using metakaolin of south African origin were analyzed in the range of 1800 to $400 \mathrm{~cm}^{-1}$ and depicted in Fig.6. The effect of different alkalinities concentrations was investigated using FTIR spectra. The metakaolin infrared spectra display peaks at broadband number 457, 566, 697, 803, and 1019. The FTIR broadband of metakaolin spectral range from around $1019 \mathrm{~cm}^{-1}$ to around $697 \mathrm{~cm}^{-1}$ as in spectra (a), assigned to Al-O bonding in Al2O3 which is absent in the synthesized zeolite (b, c, d, and e) [7]. The spectral band $1019 \mathrm{~cm}^{-1}$ of metakaolin shifted to 990 , 987, $985 \mathrm{~cm}^{-1}$ Fig.6 (b, c, d), and are assigned to antisymmetric stretching of $\mathrm{Si}$ or $\mathrm{Al}$ in zeolite structure and are converted to aluminosilicate during the reaction between metakaolin and alkaline solution. The weak intensity of zeolite $\mathrm{A}$ is observed at $562 \mathrm{~cm}^{-1}$ and could be the commencement of crystallization of double-ring zeolite A [10]. The presence of $458 \mathrm{~cm}^{-1}$ and 669 $\mathrm{cm}^{-1}$ are assigned to TO4 and asymmetric stretching of zeolite A. The spectral band between 695 to $795 \mathrm{~cm}^{-1}$ (b to d) are assigned to symmetric vibrations T-O-T of zeolite [7]. The waveband between 425 to $559 \mathrm{~cm}^{-1}$ are links to internal vibration of tetrahedral T-O-T of Si-O and Al-O sodalite modes. The infrared band of $1639 \mathrm{~cm}^{-1}$ are assigned to the framework of zeolite water [14]. The FTIR wave bands number of the reference zeolite A are 1000, 796, 696, 564 and $447 \mathrm{~cm}^{-1}$ as shown in Fig. 6e.

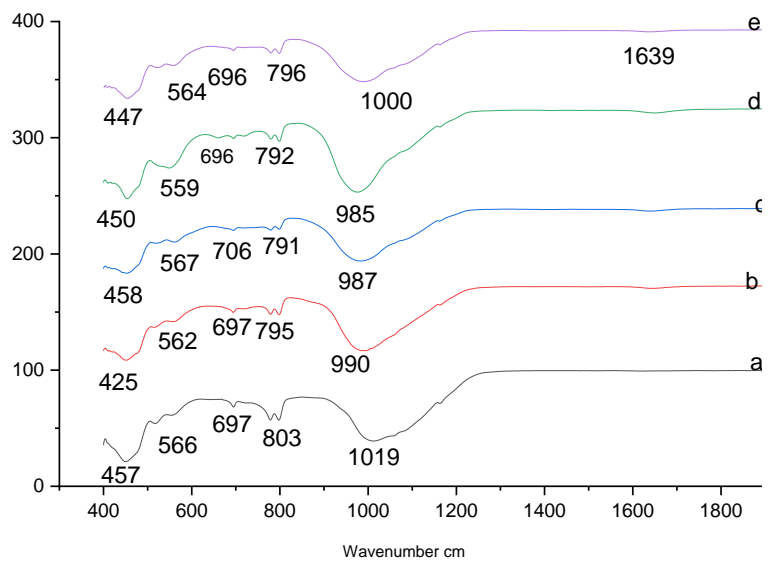

Fig. 6. The Wavebands of zeolite A and related results obtained by conventional hydrothermal process (a) Metakaolin (b) $2 \mathrm{M} \mathrm{NaOH}$ (c) $3 \mathrm{M} \mathrm{NaOH}$ (D) $4 \mathrm{M} \mathrm{NaOH} €$ Reference Sample

\section{CONCLUSIONS}

The conclusion of this research are drawn based on XRD, SEM and FTIR analysis of synthesized zeolite A after subjecting the metakaolin to react with different alkaline $(\mathrm{NaOH})$ concentrations at a fixed temperature of crystallization of 100 for $20 \mathrm{~h}$. Zeolite A was synthesized hydrothermally using beneficiated metakaolin as an alternative source of silica and alumina. The XRD pattern analysis established an outstanding crystallinity relative to the reference zeolite A sample. A round-headed edge cubic crystal was obtained by SEM. The SEM analysis shows that the crystals size increases as the alkaline concentration increases and the best crystal formed when the alkaline concentration is $4 \mathrm{M}$. In FTIR the wavebands were studied and established as typical zeolite A. The bands that 
are characteristic to zeolite A were found in the region of $125-945,800-650$ and $500-425 \mathrm{~cm}^{-1}$.

\section{REFERENCES}

[1] L. A. Regassa, "Synthesis and Characterization of Zeolite A from Kaolin of Ethiopia: Studies of its application as a detergent builder and in tannery wastewater treatment Lijalem Ayele Regassa A Thesis Submitted to Department of Chemistry Presented in Fulfillment of the R," 2016.

[2] O. O. Ltaief, S. Siffert, S. Fourmentin, and M. Benzina, "Synthesis of Faujasite type zeolite from low-grade Tunisian clay for the removal of heavy metals from aqueous waste by batch process: Kinetic and equilibrium study," Comptes Rendus Chim., vol. 18, no. 10, pp. 1123-1133, 2015.

https://doi.org/10.1016/j.crci.2015.03.013

[3] C. Belviso, F. Cavalcante, A. Lettino, and S. Fiore, "Applied Clay Science A and X-type zeolites synthesised from kaolinite at low temperature," Appl. Clay Sci., vol. 80-81, pp. 162-168, 2013. https://doi.org/10.1016/j.clay.2013.02.003

[4] A. Áurea, B. Maia, R. F. Neves, R. S. Angélica, and H. Pöllmann, "Applied Clay Science Synthesis, optimisation and characterisation of the zeolite $\mathrm{NaA}$ using kaolin waste from the Amazon Region . Production of Zeolites KA, MgA and CaA,” Appl. Clay Sci., vol. 108, pp. 55-60, 2015.

https://doi.org/10.1016/j.clay.2015.02.017

[5] J. Q. Wang, Y. X. Huang, Y. Pan, and J. X. Mi, "New hydrothermal route for the synthesis of high purity nanoparticles of zeolite $y$ from kaolin and quartz," Microporous Mesoporous Mater., vol. 232, pp. 77-85, 2016. https://doi.org/10.1016/j.micromeso.2016.06.010

[6] T. V. Ojumu, P. W. Du Plessis, and L. F. Petrik, "Synthesis of zeolite A from coal fly ash using ultrasonic treatment - A replacement for fusion step," Ultrason. Sonochem., vol. 31, pp. 342-349, 2016. https://doi.org/10.1016/j.ultsonch.2016.01.016

[7] M. Gougazeh and J. C. Buhl, "Synthesis and characterization of zeolite A by the hydrothermal transformation of natural Jordanian kaolin," J. Assoc. Arab Univ. Basic Appl. Sci., vol. 15, no. 1, pp. 35-42, 2014. https://doi.org/10.1016/j.jaubas.2013.03.007

[8] J. Wang, Y. Huang, Y. Pan, and J. Mi, "Microporous and Mesoporous Materials Hydrothermal synthesis of high purity zeolite A from natural kaolin without calcination," Microporous Mesoporous Mater., vol. 199, pp. 50-56, 2014.

https://doi.org/10.1016/j.micromeso.2014.08.002

[9] L. Ayele, J. Pérez-Pariente, Y. Chebude, and I. Díaz, "Conventional versus alkali fusion synthesis of zeolite A from low-grade kaolin," Appl. Clay Sci., vol. 132-133, pp. 485-490, 2016. https://doi.org/10.1016/j.clay.2016.07.019

[10] L. Ayele, J. Pérez-Pariente, Y. Chebude, and I. Díaz, "Synthesis of zeolite A from Ethiopian kaolin," Microporous Mesoporous Mater., vol. 215, pp. 29-36, 2015. https://doi.org/10.1016/j.micromeso.2015.05.022

[11] S. A. Kovo, "Development of zeolites and zeolite membranes from Ahoko Nigerian Kaolin,” Dr. thesis. Univ. Manchester, Engl., 2011.

[12] S. Kahraman, "Characterization of silica polymorphs in kaolins by X-ray diffraction before and after phosphoric acid digestion and thermal treatment us," vol. 552, pp. 201-206, 2005. https://doi.org/10.1016/j.aca.2005.07.045

[13] M. M. J. Treacy, "Collection of Simulated XRD Powder Patterns for Zeolites Editors :" 2001.

[14] W. P. U. D Hartanto1,*, A B Pambudi1, D N Cahyanti1, "On The Synthesis of ZSM-5 Directly from Kaolin Bangka with Aging Time On The Synthesis of ZSM-5 Directly from Kaolin Bangka with Aging Time," 2019.

https://doi.org/10.1088/1757-899X/588/1/012039 